\title{
Cyclin D3 deficiency inhibits skin tumor development, but does not affect normal keratinocyte proliferation
}

\author{
SUNG HYUN LEE ${ }^{1}$, XIAN WANG ${ }^{2}$, SUN HYE KIM $^{3}$, YONGBAEK KIM ${ }^{4}$ and MARCELO L. RODRIGUEZ-PUEBLA ${ }^{1}$ \\ ${ }^{1}$ Department of Molecular Biomedical Sciences, The Center for Human Health and The Environment and \\ The Comparative Medicine Institute, North Carolina State University, Raleigh, NC 27607; ${ }^{2}$ Department of Pathology, \\ University of Pittsburgh Cancer Institute, Pittsburg, PA 15232, USA; ${ }^{3}$ Department of Biochemistry, University of Lausanne, \\ CH-1015 Lausanne, Switzerland; ${ }^{4}$ The Laboratory of Veterinary Clinical Pathology, College of Veterinary Medicine, \\ Seoul National University, Gwanak, Seoul 151-742, Republic of Korea
}

Received February 3, 2017; Accepted May 23, 2017

DOI: $10.3892 / \mathrm{ol} .2017 .6551$

\begin{abstract}
Rearrangement and amplification of the D-type cyclin genes have been reported in human cancer. Previous studies have demonstrated that Ras-mediated skin tumorigenesis depends on pathways that act through cyclin D1 and D2; however, the role of cyclin D3 remains unknown. The present study demonstrates that cyclin D3 ablation does not affect keratinocyte proliferation, but instead increases apoptosis levels in the bulge region of the hair follicle. Consequently, cyclin D3 ablation reduces skin papilloma development in a Ras-dependent carcinogenesis model. Previous results revealed that cyclin D3 preferentially binds to cyclin-dependent kinase 6 (CDK6) in mouse keratinocytes and transgenic expression of CDK6 (K5CDK6 mice) inhibits skin tumor development. Thus, we hypothesized that the inhibitory effect of CDK6 is dependent on cyclin D3 expression. To test this hypothesis, a mouse model that overexpresses CDK6 and does not express cyclin D3 (K5CDK6/cyclin $\mathrm{D} 3^{-/}$compound mouse) was developed. Biochemical analysis of the epidermis of $\mathrm{K} 5 \mathrm{CDK} 6 /$ cyclin $\mathrm{D} 3^{-/}$mice revealed that cyclin D3 ablation resulted in increased expression of cyclin D1 protein, with a consequent elevation in the level of CDK6/cyclin D1 and CDK4/cyclin D1 complexes. These findings were concurrent with the increase skin papilloma malignant progression observed in $\mathrm{K} 5 \mathrm{CDK} 6 /$ cyclin D $^{-/-}$mice. In summary the absence of cyclin D3 led to fewer number of papillomas in cyclin D3-ablated mice than in the wild-type owing to increased apoptosis, suggesting that alterations in
\end{abstract}

Correspondence to: Dr Marcelo L. Rodriguez-Puebla, Department of Molecular Biomedical Sciences, The Center for Human Health and The Environment and The Comparative Medicine Institute, North Carolina State University, 1060 William Moore Drive, Raleigh, NC 27607, USA

E-mail: mrodriguez@ncsu.edu

Key words: skin, epidermis, papillomas, cyclin D3, cyclin-dependent kinase 6 , cell cycle cell survival are a crucial mechanism for crippling cellular defense against neoplasia. The results of the current study also suggest that although cyclin D3 expression does not alter the tumor suppressive role of CDK6 in skin carcinogenesis, the compensatory increase in cyclin D1 can shift the balance towards malignant progression.

\section{Introduction}

Cell growth and differentiation require accurate control of the mechanism regulating the entry into, passage through, and withdrawal from the cell cycle. Progress through the G1 phase of the cell cycle is mediated by the D-type cyclin family, which are key regulators of the cyclin-dependent kinases (CDKs) 4 and 6 (1,2). D-type cyclins/CDK complexes are key cell-cycle regulators, which phosphorylate critical substrates for cell-cycle progression, including the retinoblastoma $(\mathrm{pRb})$ family of proteins (3-6). Therefore, CDK4, CDK6 and D-type cyclins serve as master integrators in the G1 phase and couple with cell cycle mitogenic signals to mediate their oncogenic properties in cancer cells (6-8). The highly conserved sequence among the three D-type cyclins suggests that they serve redundant roles. However, each member is expressed in a tissue-specific manner $(1,9)$. Consistent with their role in cell proliferation, abnormal levels of D-type cyclins have been associated in the development of various types of human cancer. The rearrangement and/or amplification of the cyclin D1 gene has been widely reported in a range of human cancers, including carcinoma of the uterine cervix, breast carcinomas, and head and neck squamous cell carcinomas (10-12). Likewise, overexpression of the cyclin D2 gene have been documented in testicular tumors $(13,14)$ and B-cell malignancies (15). The deregulated expression of cyclin D3 has also been described in several types of human cancer (16-19), including malignancies of the thymus (20). Consistent with these results, Sicinska et al (21) reported that mice deficient in cyclin D3 exhibited specific defects in T-lymphocyte development. Previous studies have employed the mouse skin model to study the role of D-type cyclins in normal and neoplastic proliferation (22-26). These studies revealed that cyclin D1 and D2 are overexpressed in mouse skin papillomas and squamous-cell 
carcinomas (SCC), whereas levels of cyclin D3 protein remain constant in skin tumors (27). Previous studies have demonstrated that Ras-mediated skin tumorigenesis is dependent on pathways that signal preferentially through cyclin D1 and D2. Consistent with this idea, it was demonstrated that ablation of cyclin D1 or cyclin D2 led to the developmental inhibition of mouse skin papilloma $(28,29)$. Currently, the role of cyclin D3 in skin tumorigenesis remains poorly understood.

The present study investigated the effect of the genetic modification of cyclin D3 and CDK6 in skin carcinogenesis and normal keratinocyte proliferation. A number of previous studies by the present authors and the others have used the two-stage skin carcinogenesis protocol, which is a well-suited model for understanding the multistage nature of tumor progression in order to validate the importance of tumor suppressors and oncogenes in skin cancer formation and transformation (28-41). In this model of chemically induced skin tumorigenesis, tumor initiation is accomplished via a single topical application of a genotoxic carcinogen, including 7,12-dimethylbenz(a)anthracene (DMBA), which produces a heritable mutation in the Ha-Ras oncogene. Tumor promotion is induce via multiple applications of a tumor promoter, usually 12-O-tetradecanoylphorbol-13-acetate (TPA), leading to the expansion of the initiated cells. TPA induces the hyperproliferation of cells, which promotes the generation of benign tumors, or papillomas, which can, in certain cases, progress to SCC (malignant progression). In the mouse epidermis, cyclin D3 preferentially binds to CDK6 and, although counterintuitive, overexpression of CDK6 leads to inhibition of mouse skin tumorigenesis $(27,36)$. The authors have hypothesized that the tumor-inhibitory role of CDK6 depends largely on binding to cyclin D3. In the present study, cyclin D3-deficient mice were used to investigate the role of cyclin D3 in skin tumorigenesis. Compound mice overexpressing CDK6 in the absence of cyclin D3 were also assessed to determine the effect of cyclin D3 ablation in CDK6-dependent skin tumor development. The present study demonstrated that cyclin D3 deficiency reduces the number of benign skin tumors (papillomas) due to increased apoptosis in the hair follicle but does not alter normal keratinocyte proliferation. Although cyclin D3 binds preferentially to CDK6 (27), the tumor inhibition mediated by CDK6 is independent of cyclin D3. Finally, the present study revealed that modification in the D-type cyclin and CDK levels resulted in unbalanced formation of CDK/cyclin complexes leading to reduced papilloma development, but to a more aggressive tumor phenotype.

\section{Materials and methods}

Mouse models. The cyclin D3-knockout mice were provided by Dr Peter Sicinski, Department of Genetics, Harvard Medical School (Boston, MA, USA) (21), and the generation of K5CDK6 transgenic mice was as previously reported (36). Cyclin D3 ${ }^{+/}$mice were backcrossed with the FVB genetic background (The Jackson Lab, Bar Harbor, ME, USA) for three generations to reduce the influence of the genetic background. K5CDK6 mice were mated with cyclin D3 ${ }^{+/-}$mice to obtain $\mathrm{K} 5 \mathrm{CDK} 6 /$ cyclin $\mathrm{D}^{+/-}$mice and backcrossed with cyclin $\mathrm{D} 3^{+/-}$mice to acquire K5CDK6/cyclin $\mathrm{D}^{-/-}$mice. The mice were housing at the animal facility of the College of
Veterinary Medicine, NC State University. Housing conditions include a $12 \mathrm{~h} \mathrm{light/dark} \mathrm{cycle,} 20-23^{\circ} \mathrm{C}$ and water and food were accessible at all times. The genotype of the mice was confirmed by polymerase chain reaction (PCR) as previously described $(21,36)$ using KAPA2G fast PCR kit (Kapa Biosystems, Inc., Wilmington, MA, USA).

Mouse experiments. The animal research protocols were approved by the Institutional Animal Care and Use Committee at North Carolina State University (Raleigh, NC, USA). The end-point of the two-stage carcinogenesis experiments was the quantification of the number of skin tumors developed during a 20-25 weeks period or an individual skin tumor size of $1,800 \mathrm{~mm}^{3}$, at which point the animal would have reached the study end-point. Tumor burden may exceed $1,800 \mathrm{~mm}^{3}$ when multiple tumors are present but no individual tumor exceeded this dimension (tumor burden did not exceed $10 \%$ of mouse body weight). The effect of lack of cyclin D3 in skin tumorigenesis was determined with 15 female mice from each group (wild-type vs. cyclin D $3^{-/}$). No phenotypical differences were observed between wild type and cyclin $\mathrm{D} 3^{-/}$mice. Three-weeks-old mice were administered with a single topical application of $200 \mathrm{nmol}$ DMBA (Cat D3254; Sigma-Aldrich; Merck KGaA, Darmstadt, Germany) in $200 \mu \mathrm{l}$ acetone on the dorsal surface of the mice. After 2 weeks, the mice were dosed topically twice a week with $4 \mu \mathrm{g}$ TPA (Cat P1680; Sigma-Aldrich; Merck KGaA) in $200 \mu$ l acetone for 20 weeks. Papilloma development was traced weekly until the end of the experiment at 20 weeks. Tumors $\geq 1 \mathrm{~mm}$ in size were counted weekly, and the multiplicity (mean number of tumors per mouse) and incidence of tumor-bearing mice were compared between the two groups using Fisher's exact test.

To determine the effect of cyclin D3 ablation on K5CDK6 transgenic mice, four groups of 10 mice each were utilized (wild-type, K5CDK6, cyclin $\mathrm{D} 3^{-/}$and $\mathrm{K} 5 \mathrm{CDK} 6 /$ cyclin $\mathrm{D} 3^{-/-}$mice). K5CDK6 mice were generated in C57BL/6 background (36) and crossed with cyclin $\mathrm{D}^{-/-}$as aforementioned. Tumorigenesis in newborn mice was initiated at day 3 after birth with a single application of $50 \mu \mathrm{g}$ DMBA in $50 \mu$ l acetone on the dorsal skin. After 3 weeks, the mice were administered twice a week with $4 \mu \mathrm{g}$ TPA in $200 \mu \mathrm{l}$ acetone for 25 weeks. Papilloma development was traced weekly until the end of the experiment at 25 weeks after the first application of the tumor promoter TPA. Tumors $\geq 1 \mathrm{~mm}$ in size were counted weekly and the multiplicity and incidence of tumor-bearing mice were compared between the groups using Fisher's exact test.

The mice were sacrificed by $\mathrm{CO}_{2}$ asphyxiation, and the dorsal skins were treated with a commercial available depilatory agent (Nair) for $1 \mathrm{~min}$.

Western blotting and co-immunoprecipitation assays. The epidermal tissue was scraped off with a razor blade, placed into the homogenization buffer (50 mmol/1 HEPES, $\mathrm{pH} 7.5$, $150 \mathrm{mmol} / 1 \mathrm{NaCl}, 2.5 \mathrm{mmol} / 1$ EGTA, $1 \mathrm{mmol} / 1$ ethylenediaminetetraacetic acid, $0.1 \%$ Tween-20, 1 mmol/1 dithiothreitol, $0.1 \mathrm{mmol} / 1$ phennylmethyl sulfonyl fluoride, $0.2 \mathrm{U} / \mathrm{ml}$ aprotinin, $10 \mathrm{mmol} / 1 \mathrm{~b}$-glycerophosphate, $0.1 \mathrm{mmol} / 1$ sodium vanadate and $1 \mathrm{mmol} \mathrm{NaF}$ ), and homogenized using a manual homogenizer. The epidermal homogenate was centrifuged at $11,000 \mathrm{x}$ g for $20 \mathrm{~min}$ at $4^{\circ} \mathrm{C}$ to collect the supernatant, which 
was used directly for western blot analysis or stored at $-80^{\circ} \mathrm{C}$. Protein concentration was measured using the Bio-Rad Protein Assay system (Bio-Rad Laboratories, Inc., Hercules, CA, USA). Protein lysates ( $25 \mu \mathrm{g}$ from each sample) were electrophoresed on $10 \%$ acrylamide gels and electrophoretically transferred onto nitrocellulose membranes. After being blocked with $5 \%$ nonfat powdered milk in Dulbecco phosphate-buffered saline, the membranes were incubated with $1 \mu \mathrm{g} / \mathrm{ml}$ specific antibodies. The following antibodies were used: Polyclonal antibodies against cyclin D1 (sc-717), cyclin D2 (sc-593), CDK4 (sc-260), CDK6 (sc-177) and $\beta$-actin (sc-1616), (all from Santa Cruz Biotechnology, Inc., Dallas, TX, USA; all 1:100) and mouse monoclonal antibody against cyclin D3 (DCS-22) (NeoMarkers; Thermo Fisher Scientific Inc., Waltham, MA, USA). The membranes were washed 3-times on PBS and Triton X-100 (Sigma-Aldrich; Merck KGaA) and incubated with secondary antibodies: Goat anti-rabbit-HRP (horseradish peroxidase) (cat. no. sc-2020) (Santa Cruz Biotechnology, Inc.) or goat anti-mouse-HRP (cat. no. 31430) (Pierce; Thermo Fisher Scientific Inc.) and visualized using enhanced chemiluminescence (ECL detection kit; GE Healthcare Bio-Sciences, Pittsburgh, PA, USA).

To investigate CDK/D-type cyclin complex formations, $5 \mu \mathrm{g}$ of antibodies against CDK4 (100 $\mu \mathrm{g} / \mathrm{ml}$; cat. no. sc-260), CDK6 (100 $\mu \mathrm{g} / \mathrm{ml}$; cat. no. sc-177) and $5 \mu \mathrm{g}$ of normal rabbit IgG $(200 \mu \mathrm{g} / \mathrm{ml}$; cat. no. sc-2027; Santa Cruz Biotechnology, Inc.), conjugated with protein A-sepharose beads (Thermo Fisher Scientific, Inc.) or Dynabeads ${ }^{\circledR}$ Protein G (Invitrogen; Thermo Fisher Scientific, Inc.) were used. Fresh protein lysates from epidermal tissue $(250 \mu \mathrm{g})$ were immunoprecipitated for $1 \mathrm{~h}$ at $4^{\circ} \mathrm{C}$ with constant rotation. Following three washes with extraction buffer, proteins that co-immunoprecipitated were analyzed by western blot analysis as aforementioned. Protein lysate $(25 \mu \mathrm{g})$ was loaded as a control input.

Immunostaining. Epithelial cell proliferation was measured by intraperitoneal injection of $60 \mu \mathrm{g} / \mathrm{g} 5$-bromodeoxyuridine (BrdU) 30 min prior to the sacrifice of mice by $\mathrm{CO}_{2}$ asphyxiation. Dorsal skin and tumor sections were fixed in 10\% formalin (Cat. HT5014; Sigma-Aldrich; Merck KGaA) at room temperature for $48 \mathrm{~h}$ and embedded in paraffin prior to sectioning. Tissue sections (thickness, $4 \mu \mathrm{m}$ ) were stained with hematoxylin and eosin (H\&E) for $5 \mathrm{~min}$ at room temperature and were used for histopathological analysis.

BrdU incorporation was detected by immunohistochemical staining of paraffin-embedded skin and tumor sections with a mouse anti-BrdU (S7101) monoclonal antibody (Calbiochem; EMD Millipore, Billerica, MA, USA), biotin-conjugated anti-mouse antibody (Vector Laboratories, Inc., Burlingame, CA, USA), and avidin-biotin Vectastain Elite peroxidase kit (Vector Laboratories, Inc.) with diaminobenzidine as a chromogen. Apoptotic cells were identified using terminal deoxynucleotidyl transferase dUTP nick end labeling (TUNEL) assays with the FragEL DNA Fragmentation Detection kit and Colorimetric-TdT enzyme (EMD Millipore), according to the manufacturer's instructions. Briefly, the terminal deoxynucleotidyl transferase (TdT enzyme) binds to the exposed 3'OH ends of a DNA fragment generated in apoptosis progression and catalyzes the addition of biotin-labeled and unlabeled deoxynucleotides. Biotinylated nucleotides were detected using a streptavidin-HRP conjugate. The slides were counterstained with methyl green for quantification of normal and apoptotic cells. The numbers of apoptotic cells in skin tumors were determined in $250 \mu \mathrm{m}^{2}$ sections with a reticule grid using a light microscope (Nikon Eclipse E400). Apoptotic keratinocytes in interfollicular and follicular epidermis were quantified in sections (thickness, $2 \mathrm{~cm}$ ). To determine the incidence of follicular apoptosis, hair follicles with $\geq 1$ apoptotic cell in the bulge area were counted as a positive hair follicle. In all cases, 12 fields (magnification, $x 400$ ) were counted per section in a total of 10 sections representing 5 mice per genotype.

Statistical analysis. Statistical analysis [paired t-test, analysis of variance (one-way ANOVA), Bonferroni's multiple comparison test and correlation Person's test) was performed using GraphPad Prism 4 software (GraphPad Software Inc., La Jolla, CA, USA). $\mathrm{P}<0.05$ was considered to indicate a statistically significant difference.

\section{Results}

Reduced sensitivity to ras-dependent skin papilloma development in cyclin D3-null mice. The authors of the present study have previously reported that knocking out cyclin D1- and cyclin D2 has a mild effect on the proliferative status of mouse epidermis, but lead to a severe reduction in the sensitivity to the development of skin papillomas induced by chemical carcinogenesis $(28,42)$. To investigate the effect of cyclin D3 ablation in mouse skin, cyclin D3-null mice developed by gene targeting in embryonic stem cells were utilized (21). First, the authors investigated whether ablation of cyclin D3 affected epidermal homeostasis. To this end, formalin-fixed, paraffin-embedded skin cross-sections of cyclin $\mathrm{D}^{-/-}$and wild-type siblings were examined. H\&E-stained sections revealed no changes in the skin structure of cyclin D3 $3^{--}$compared with wild-type mice. No marked alterations in the morphology of the follicular and interfollicular epidermis were observed between cyclin D3 ${ }^{-/}$and wild-type siblings (Fig. $1 \mathrm{~A}$ and B). Consistent with this data, cyclin $\mathrm{D}^{-/}$and wild-type mice exhibit no differences in the total number of nucleated keratinocytes in the interfollicular epidermis. To determine whether loss of cyclin D3 affected epidermal homeostasis, the rate of keratinocyte proliferation and apoptosis was examined. Cyclin D $3^{-/-}$mice did not exhibit any detectable alterations in keratinocyte proliferation as determined by epidermal thickness (data not shown) and the number of BrdU-positive cells in the interfollicular epidermis compared with wild-type mice (Fig. 1C-E). The authors conclude that epidermal keratinocytes proliferate normally in the absence of cyclin D3, likely through compensation by other members of the D-type cyclin family.

The authors also studied whether a lack of cyclin D3 affects apoptosis in interfollicular epidermis and hair follicles. As previously reported, the number of apoptotic keratinocytes in the interfollicular epidermis was barely affected by knockout of cyclin D3 (0.2\%) (42-44), and no differences were observed between cyclin D3 ${ }^{-/-}$and wild-type mice (data not shown). Although the hair follicle stem cells do not contribute to the homeostasis of mouse epidermis. It is known that stem cells located in the bulge area of the hair follicle participate in 
A

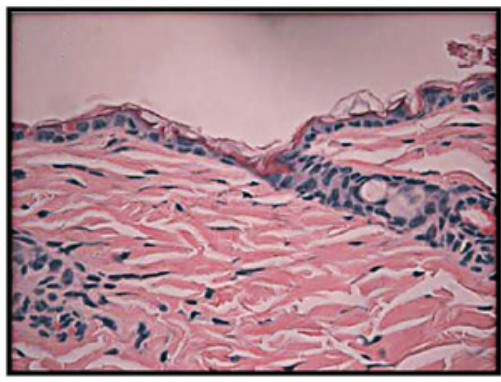

C

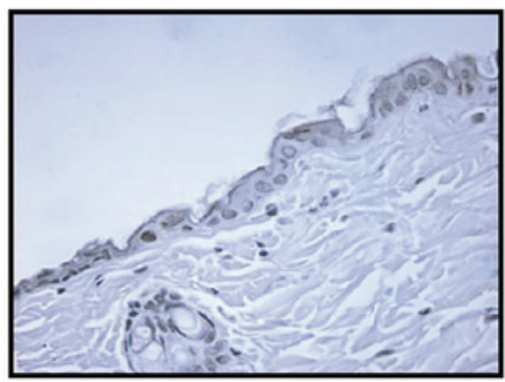

E

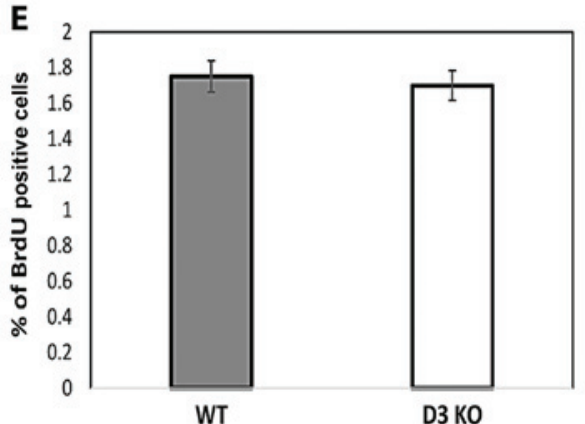

B

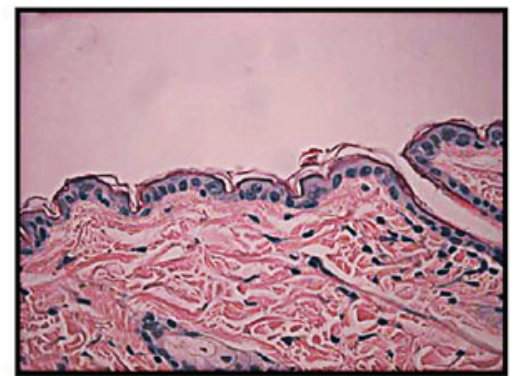

D

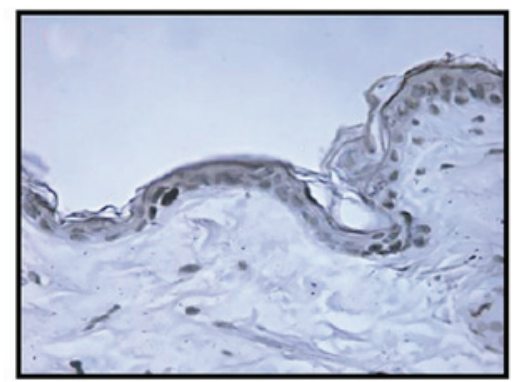

$\mathbf{F}$

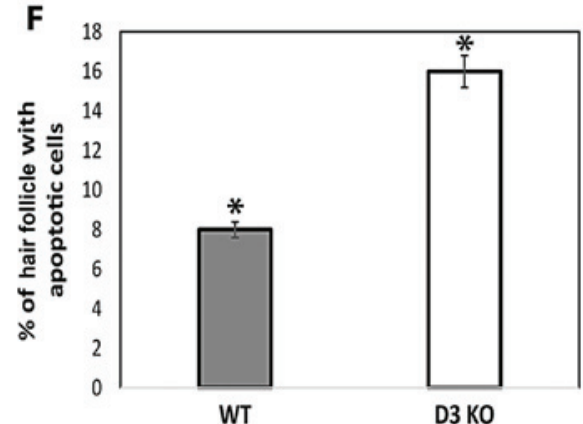

Figure 1. Skin phenotype of cyclin D3-null mice. Representative paraffin-embedded sections of skin from (A) WT mice and (B) cyclin D $3^{-/}$mice stained with hematoxylin and eosin. BrdU labeling of sections from (C) WT and (D) cyclin D3 ${ }^{-/}$mice detected using anti-BrdU antibody. Magnification, $\mathrm{x} 400$. (E) In vivo proliferation assay using BrdU staining in the basal cell layer of mouse epidermis. (F) Increased incidence of apoptotic cells in the bulge region of hair follicle from cyclin $\mathrm{D}^{-/}$mice compared with WT siblings ( $\mathrm{n}=5,{ }^{*} \mathrm{P}<0.001$, t-test). BrdU, bromodeoxyuridine; KO, knockout; WT, wild-type.

A

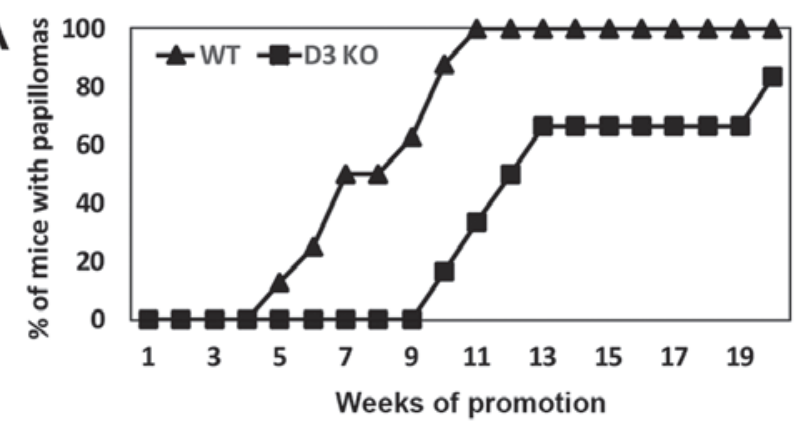

B

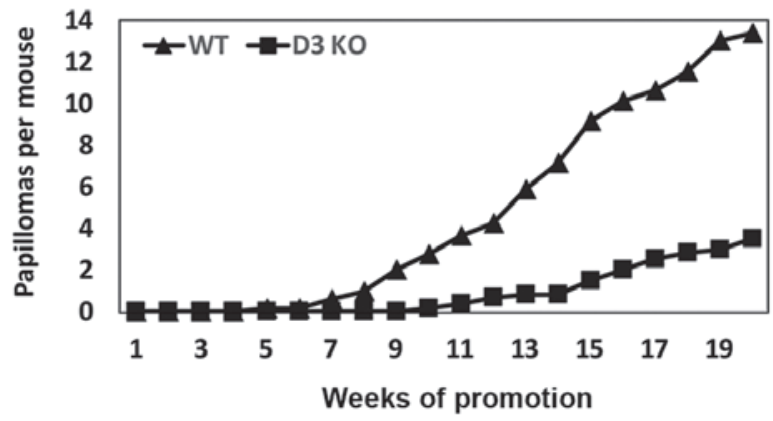

Figure 2. Kinetics of cyclin D3 ${ }^{-/}$skin papilloma development. WT and cyclin D3 ${ }^{-/}$siblings were initiated with 7,12-dimethylbenz[a]anthracene and promoted with multiple applications of 12-O-tetradecanoylphorbol-13-acetate on dorsal mouse skin. (A) Incidence of papilloma, defined as the percentage of mice with $\geq 1$ papilloma, as a function of weeks of study. (B) Multiplicity, defined as the average number of papillomas per mouse, as a function of weeks of study. $n=15$ for each experimental group. WT, wild-type; D3 KO, cyclin D3 ${ }^{-/}$knockout.

hyperproliferative conditions, including epidermis regeneration hyperproliferation conditions (45). Therefore, the number of hair follicles carrying apoptotic cells in the bulge region was quantified to determine the incidence of apoptosis in hair follicles. A two-fold increase was observed in the number of hair follicles carrying apoptotic cells in cyclin $\mathrm{D}^{-/}$mice compared with wild-type siblings $(\mathrm{P}<0.001$, t-test) (Fig. 1F).
Supporting the data of the present study, it was previously reported that downregulation of cyclin D3 also results in increased apoptosis in leukemia cells (46). Importantly, multipotent stem cells localized in the bulge region of the mouse hair follicle retain chemical carcinogens and have been hypothesized as the origin of skin papillomas $(47,48)$. Consequently, the authors next asked whether increased apoptosis observed 
Table I. Cdk/D-type cyclin complexes in mouse epidermis.

\begin{tabular}{lcccc}
\hline Mouse genotype & CDK6/cyclin D1 & CDK6/cyclin D3 & CDK4/cyclin D1 & CDK4/cyclin D3 \\
\hline Wild-type & + & + & + & + \\
K5CDK6 & + & +++ & + & + \\
Cyclin D3 & +- & - & +++ & - \\
K5CDK6/cyclin D3 & $-/-$ & + & +++ & -
\end{tabular}

CDK/D-type cyclin complexes were determined by co-immunoprecipitation assays with anti-CDK4 and CDK6 antibodies and analyzed by western blotting with anti-D-type cyclin antibodies. CDK, cyclin-dependent kinase. (-), not determined; (+), value of CDK/cyclin complexes defined in wild-type mice or less than the wild-type value; $(+++)$, value two-fold or greater than wild-type mice.

throughout the bulge region of cyclin $\mathrm{D} 3^{-/-}$mice would affect skin papilloma development. To test this hypothesis, cyclin $\mathrm{D}^{-/-}$and wild-type littermates were subjected to the two-stage carcinogenesis protocol. This protocol induces skin papillomas after a single application of a carcinogen followed by biweekly treatments with a tumor promoter that favors the selection of cells bearing Ha-ras mutations. The dorsal skin of cyclin D $3^{-/-}$and wild-type littermates were topically treated with a sub-carcinogenic dose of the genotoxic DMBA, and tumor development was subsequently promoted via biweekly applications of 12-O-tetradecanoylphorbol-13-acetate (TPA) for 20 weeks. The incidence and multiplicity of papillomas were scored in each group for 20 weeks. Papilloma development was delayed by 5 weeks in cyclin D3-null mice compared with wild-type siblings (Fig. 2A). The incidence of papilloma formation reached a plateau of $100 \%$ at 11 weeks in wild-type mice. By contrast, cyclin D $3^{-/-}$mice reached $83 \%$ of papilloma incidence at 20 weeks, with $\sim 20 \%$ of the cyclin D3 ${ }^{-/}$mice remaining refractory to tumor development (Fig. 2A). Tumor multiplicity (mean number of tumors per mice) shows a $74 \%$ reduction in cyclin $\mathrm{D}^{-/}$mice compared with control littermates (Fig. 2B).

Collectively, these observations demonstrate that cyclin D3 ablation does not grossly affect follicular and interfollicular keratinocyte proliferation, but leads to increase apoptosis in the bulge region of the hair follicle and decreased papilloma development.

Lack of cyclin D3 does not affect the tumor inhibitory activity of CDK6. Similar to cyclin D3 ablation, the authors have shown previously that transgenic expression of CDK6 results in increased apoptosis in the hair follicle and a reduced number of skin papillomas in a two-stage carcinogenesis model (36). Notably, the authors have previously determined a preferential binding of cyclin D3 to CDK6 and the consequent increase in CDK6/Cyclin D3 complex formation in hyperproliferative epidermis (49). Likewise, forced expression of CDK6 in epidermis of K5CDK6 transgenic mice led to increased binding to cyclin D3 (36). Therefore, the authors asked whether cyclin D3 expression is essential for the tumor inhibitory activity of CDK6 (36). To test this hypothesis, the authors developed the $\mathrm{K} 5 \mathrm{CDK} 6 /$ cyclin $\mathrm{D} 3^{-/}$compound mice in which overexpression of CDK6 is driven by the keratin 5 promoter (K5) to the basal cell layer of epidermis and hair follicles in a cyclin D3-null background. Newborn animals did not display any evident developmental abnormalities, and $\mathrm{H} \& \mathrm{E}$ staining of the dorsal epidermis did not reveal alterations in the morphology of follicular and interfollicular epidermis. Furthermore, no significant differences in the number of nucleated cells were observed in the interfollicular epidermis (data not shown).

To determine whether simultaneous overexpression of CDK6 and lack of cyclin D3 affects the expression of other cell-cycle regulators, biochemical analysis of epidermal tissue was performed. Protein analysis confirmed elevated CDK6 expression and a lack of cyclin D3 in the epidermis of K5CDK6/cyclin D3 ${ }^{-/}$mice (Fig. 3A). Notably, a marked increase in the cyclin D1 protein level from cyclin D3 ${ }^{-/-}$and $\mathrm{K} 5 \mathrm{CDK} 6 /$ cyclin D3 ${ }^{-/-}$ epidermis compared with K5CDK6 and wild-type samples was observed (Fig. 3A). A mild increase in cyclin D2 protein expression was detected in K5CDK6 and cyclin D3 ${ }^{-/}$epidermis. However, this effect varied between samples.

D-type cyclins are the limiting factors during CDK/cyclin complex formation. Therefore, modifications in the protein levels of cyclin D1 may change the kinetics of complex formation in mouse epidermis $(27,50)$. In fact, the forced expression of cyclin D3 in mouse epidermis resulted in elevated CDK6 and CDK4 activity, primarily associated with increase formation of CDK4/cyclin D1, CDK6/cyclin D1 and CDK6/cyclin D3 complexes (29). Therefore, whether transgenic expression of CDK6 alters D-type cyclins/CDKs complex formation was analyzed. Epidermal lysates from wild type, K5CDK6, cyclin D $^{-/}$and K5CDK6/cyclin D3 ${ }^{-/}$mice were immunoprecipitated with antibodies against CDK6 and CDK4 followed by western blot analysis to determine associations between cyclin D1 and cyclin D3. In agreement with previous findings, it was indicated that the overexpression of CDK6 resulted in elevated levels of CDK6/cyclin D3 complex in the epidermis of K5CDK6, compared with wild-type littermates (Fig. 3B; Table I) (36). Expression of CDK6 was barely visible in the epidermis of wild-type and cyclin D3 $3^{-/}$mice (Fig. 3A and $\mathrm{B}$ ). Consistent with the elevated protein level of cyclin D1, K5CDK6/cyclin D3 ${ }^{-/}$epidermis exhibited higher levels of CDK6/cyclin D1 complexes compared with K5CDK6 epidermis (Fig. 3B; Table I). In addition, epidermis from K5CDK6/cyclin D3 ${ }^{-/}$and cyclin D3 ${ }^{-/}$mice displayed higher levels of CDK4/cyclin D1 complex formation compared with wild-type and K5CDK6 mice (Fig. 3C; Table I). These results confirm that, in the absence of cyclin D3, the compensatory increase in cyclin D1 expression leads to increased complex 

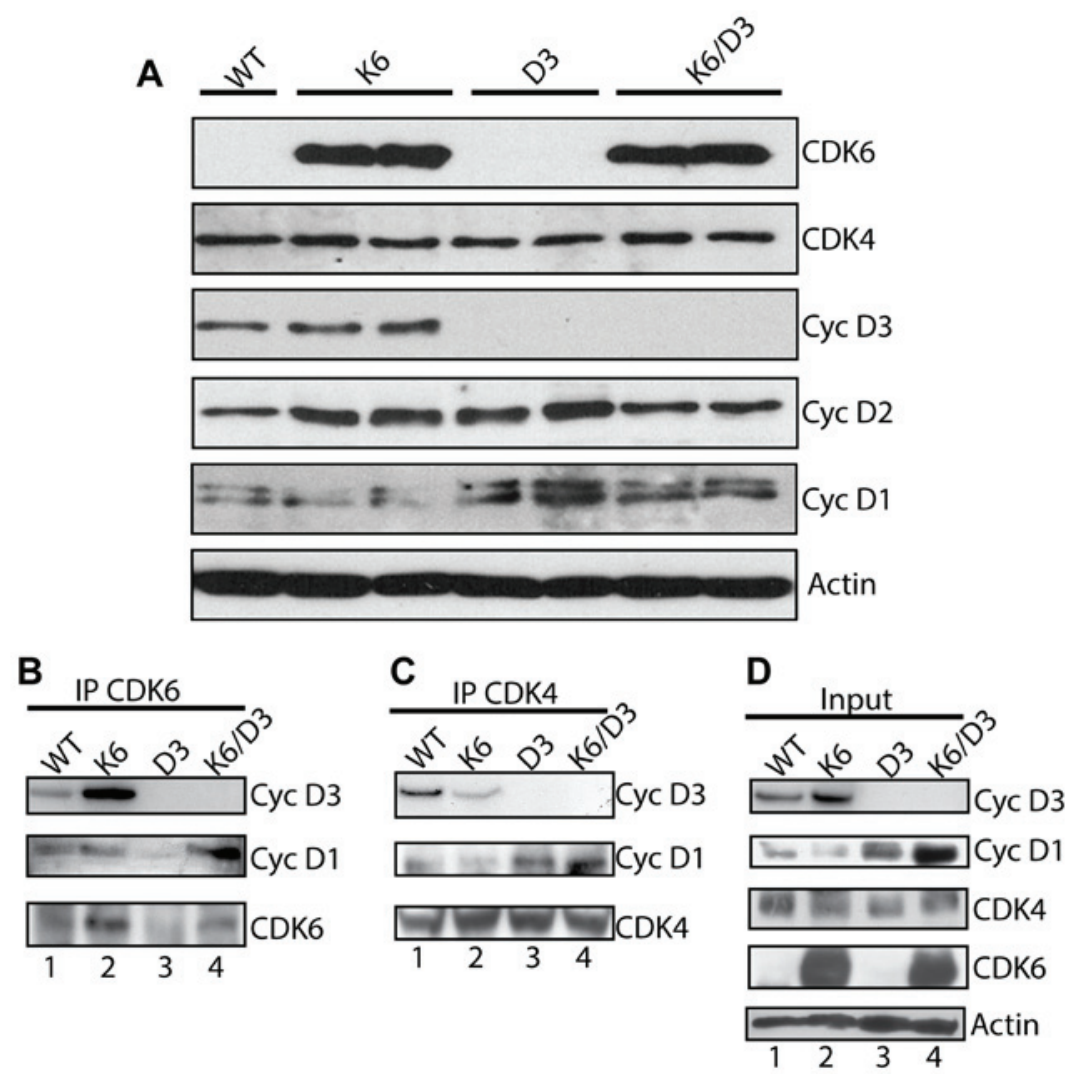

Figure 3. Biochemical analysis of cell cycle regulators in mouse epidermis. Epidermal lysates from WT, K6, D3 and K6/D3 mice were separated by SDS-PAGE and transferred onto a nitrocellulose membrane. Primary antibodies against CDK6, CDK4, cyclin D3, cyclin D2 and cyclin D1 were used for immunoblot analysis. $\beta$-actin was used as a loading control. (A) Epidermal lysates from WT, K6, D3 and K6/D3 mice were immunoprecipitated with antibodies against (B) CDK6 or (C) CDK4 and blotted with antibodies against cyclin D3, cyclin D1, CDK6 and CDK4. (D) Epidermal lysates from WT, K6, D3 and K6/D3 mice were loaded. CDK, cyclin-dependent kinase; K6, K5CDK6 mice; D3, cyclin D3 ${ }^{-/}$mice; K6/D3, K5CDK6/cyclinD3 ${ }^{-/}$mice WT, wild-type; IP, immunoprecipitation.
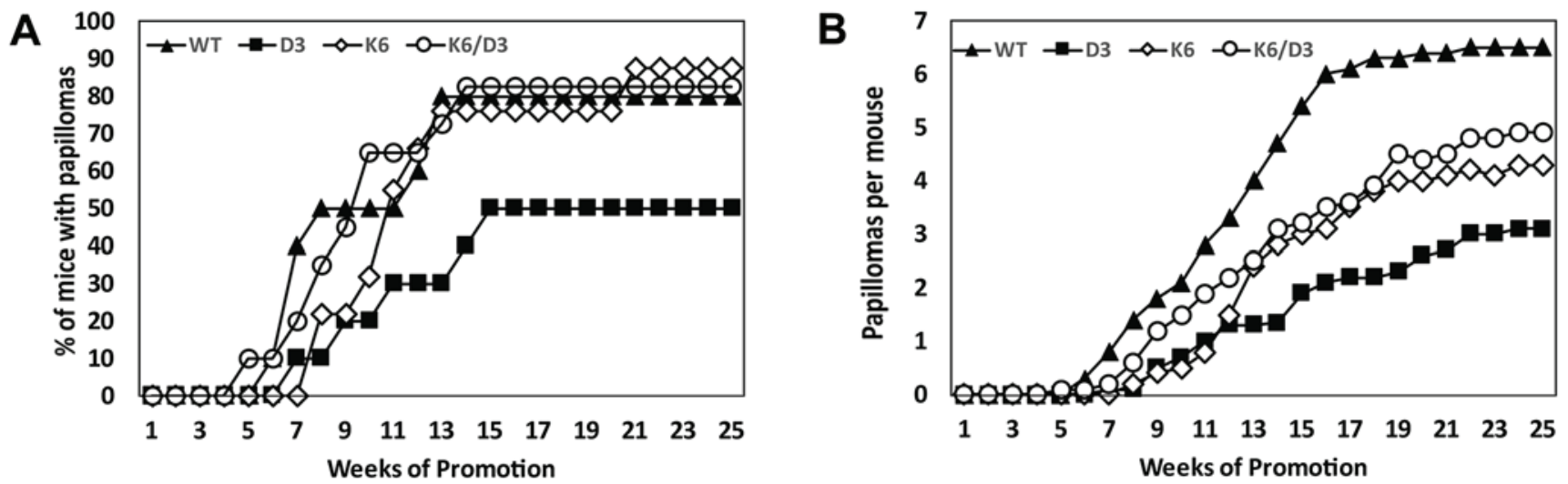

Figure 4. Kinetics of cyclin K5CDK6/D3 ${ }^{-/}$skin papilloma development. WT, cyclin D3 $3^{-/}$, K5CDK6 and K5CDK6/cyclin D3 $3^{--}$siblings were initiated with 7,12-dimethylbenz[a]anthracene and promoted with multiple applications of 12-O-tetradecanoylphorbol-13-acetate on dorsal mouse skin. (A) Incidence of papilloma (percentage of mice with $\geq 1$ papilloma) as a function of weeks of study. (B) Multiplicity (average number of papillomas per mouse) as a function of weeks of study. WT, wild-type; K6, K5CDK6 mice; D3, cyclin D3- mice; K6/D3, K5CDK6/cyclin D3- mice.

formation with the two main CDKs of the G1 phase, CDK4 and CDK6. Expression levels of CDK6, CDK4, and cyclin D1 were quantified in protein lysates (input) and immunoprecipitated samples from $\mathrm{K} 5 \mathrm{CDK} 6 /$ cyclin $\mathrm{D}^{-/}$and cyclin $\mathrm{D}^{3^{--}}$mice to determine the ratio of input to immunoprecipitation. It was established that the majority of cyclin D1 proteins bind to CDK4 in cyclin $\mathrm{D}^{-1-}$ and K5CDK6/cyclin $\mathrm{D}^{-/}{ }^{-}$epidermis, whereas in wild-type and K5CDK6 epidermis only $12 \%$ of cyclin D1 binds to CDK4. The observation that CDK6 is not expressed at high levels in wild-type and cyclin D ${ }^{-/}$epidermis does not allow for verification of the ratio of cyclins to CDK6 complexes. The authors conclude that a lack of cyclin D3 lead to changes in cyclin D1 protein level, which favors the formation of CDK4/cyclin D1 and CDK6/cyclin D1 complexes in K5CDK6/D3 $3^{--}$mice and CDK4/cyclin D1 complexes in cyclin $\mathrm{D}^{-/}$mice. Therefore, a lack of cyclin 
Table II. Histopathological analysis of skin tumors.

Tumor type

\begin{tabular}{lccc} 
Mouse genotype & Analyzed tumors per group, $\mathrm{n}$ & Papilloma $^{\mathrm{a}}, \mathrm{n}(\%)$ & $\mathrm{SCC}^{\mathrm{b}}, \mathrm{n}(\%)$ \\
\hline Wild-type & 21 & $18(86)$ & $3(14)$ \\
K5CDK6 & 20 & $17(85)$ & $3(15)$ \\
Cyclin D3 $^{-/}$ & 10 & $10(100)$ & $0(0)$ \\
K5CDK6/cyclin D3 $^{-/}$ & 24 & $14(58)$ & $10(42)$
\end{tabular}

${ }^{a}$ No atypia observed in basal layers, basal cell hyperplasia and no invasion of epidermal cells into the dermis. ${ }^{\mathrm{b}}$ Atypia in basal and certain suprabasal layers. Differentiated or highly undifferentiated premalignant papilloma's and SCC with expansion of basal and spinous layer, loss of polarity, and cords of epidermal cells contiguous to the basal layer invading the dermis. SCC, squamous cell carcinoma.

D3 is at least partially compensated by increased cyclin D1 protein in mouse epidermis.

In order to define whether cyclin D3 expression is essential for the tumor-inhibitory role of CDK6 (36), K5CDK6/cyclin $\mathrm{D}^{-/}$, K5CDK6, cyclin D3 $3^{-/}$and wild-type littermates were subjected to the two-stage carcinogenesis protocol for 25 weeks. The four groups developed visible papillomas between 5-8 weeks of carcinogenic promotion (Fig. 4A). Whereas wild-type, $\mathrm{K} 5 \mathrm{CDK} 6$ and $\mathrm{K} 5 \mathrm{CDK} 6 / \mathrm{D}^{-/}$mice reached $50 \%$ of incidence by 8-11 weeks, cyclin $\mathrm{D}^{-/-}$mice exhibited delayed development of skin papillomas and reached 50\% incidence after 15 weeks of promotion $(\mathrm{P}=0.001$, $t$-test $)$, remaining at this value until the end of the experiment. In addition, the incidence of papilloma formation of $\mathrm{K} 5 \mathrm{CDK} 6, \mathrm{~K} 5 \mathrm{CDK} 6 / \mathrm{D}^{-1 /}$ and wild-type mice reached a plateau of $\sim 80 \%$ at 13-14 weeks ( $\mathrm{P}=0.001$, t-test; Fig. 4A). As previously reported, K5CDK6 mice display a significantly lower number of papillomas per mouse (multiplicity) compared with wild-type mice ( $34 \%$ reduction at 25 weeks, $P=0.01$, t-test; Fig. 4B) (36). In support of the findings in the present study (Fig. 2B), cyclin $\mathrm{D}^{-/-}$mice exhibited the strongest inhibition of papilloma multiplicity among the four groups (52\% reduction, $\mathrm{P}=0.0002$, t-test; Figs. 2B and 4B). Tumor inhibition of K5CDK6/cyclin $\mathrm{D}^{-/}$mice was similar to K5CDK6 mice, which displayed a $25 \%$ reduction in multiplicity compared with wild-type mice ( $\mathrm{P}=0.04$, t-test; Fig. 4B). Importantly, papilloma incidence and multiplicity between $\mathrm{K} 5 \mathrm{CDK} 6$ and $\mathrm{K} 5 \mathrm{CDK} 6 /$ cyclin $\mathrm{D}^{-1-}$ mice showed no statistically significant differences. Therefore, the authors confirm that ablation of cyclin D3 causes severe papilloma repression (Figs. 2 and 4), but the tumor inhibition driven by overexpression of CDK6 is independent of cyclin D3 expression.

Lack of cyclin D3 reduces keratinocyte proliferation and increases apoptosis in skin papillomas. The simultaneous overexpression of CDK6 and ablation of cyclin D3 led to changes in the kinetics of CDK/D-type cyclin complex formation, but did not disturb the proliferative status of mouse keratinocytes (Fig. 3). To investigate the biological determinants responsible for the reduced number of papillomas observed upon variation in the levels of CDK6 and cyclin D3, the authors monitored possible alterations in proliferation and apoptosis.
On the last day of the study, remaining animals were injected with BrdU solution, and tumors were collected and preserved in formalin. Paraffin-embedded tumors were immunostained to determine the number of cells in S phase by BrdU incorporation analysis. The proliferation status of cyclin D ${ }^{-/}$keratinocytes exhibited a 0.5 -fold reduction compared with wild-type tumors $(\mathrm{P}<0.05$, Bonferroni's multiple comparisons test; Fig. 5). By contrast, keratinocyte proliferation increased by 1.5 -fold in $\mathrm{K} 5 \mathrm{CDK} 6$ and $\mathrm{K} 5 \mathrm{CDK} 6 /$ cyclin $\mathrm{D}^{--}$mouse papillomas compared with the wild-type $(\mathrm{P}<0.05$, Bonferroni's multiple comparisons test; Fig. 5). Therefore, no positive association was observed between the reduced papilloma development of cyclin D3 ${ }^{-/}$and K5CDK6 mice and their proliferative status. In order to define whether other mechanisms compensate for the changes detected in keratinocyte proliferation, the number of apoptotic keratinocytes in papillomas was monitored by TUNEL labeling. Notably, papillomas from genetically modified mice exhibited elevated apoptosis compared with wild-type tumors (Fig. 6). Consistent with a previous study by the authors (36), papillomas from K5CDK6 mice displayed a 2.4-fold increase in apoptosis compared the wild-type $(\mathrm{P}<0.05$, Bonferroni's multiple comparisons test). Likewise, papillomas from cyclin $\mathrm{D}^{-/-}$and $\mathrm{K} 5 \mathrm{CDK} 6 /$ cyclin $\mathrm{D}^{-/}$mice exhibited a 2-fold increase in the number of apoptotic keratinocytes compared with wild-type tumors $(\mathrm{P}<0.05$, Bonferroni's multiple comparisons test; Fig. 6). In agreement with these results, a recent study demonstrated that overexpression of CDK6 and cyclin D1 inhibits cell differentiation and causes increased apoptosis (51). The BrdU index and the number of apoptotic cells in K5CDK6, cyclin $\mathrm{D}^{-/}$and $\mathrm{K} 5 \mathrm{CDK} 6 /$ cyclin $\mathrm{D} 3^{-/}$tumors were normalized to the corresponding values of wild-type samples (Figs. 5 and 6), and the rate of apoptosis/proliferation was calculated for each genotype (A/P index). A positive correlation was observed between the reduced number of papillomas (multiplicity) and the increased apoptotic/proliferation index (Pearson's test, $\mathrm{P}=0.0169$; Fig. $6 \mathrm{E}, \mathrm{A} / \mathrm{P}$ index). These results suggest that changes in the levels of CDK/D-type cyclin complexes can serve a role altering the rate of proliferation and apoptosis leading to modifications in the kinetic of mouse skin tumor development.

To determine whether modifications in CDK6 and cyclin D3 levels and the consequent changes in the level of CDK4/cyclin 

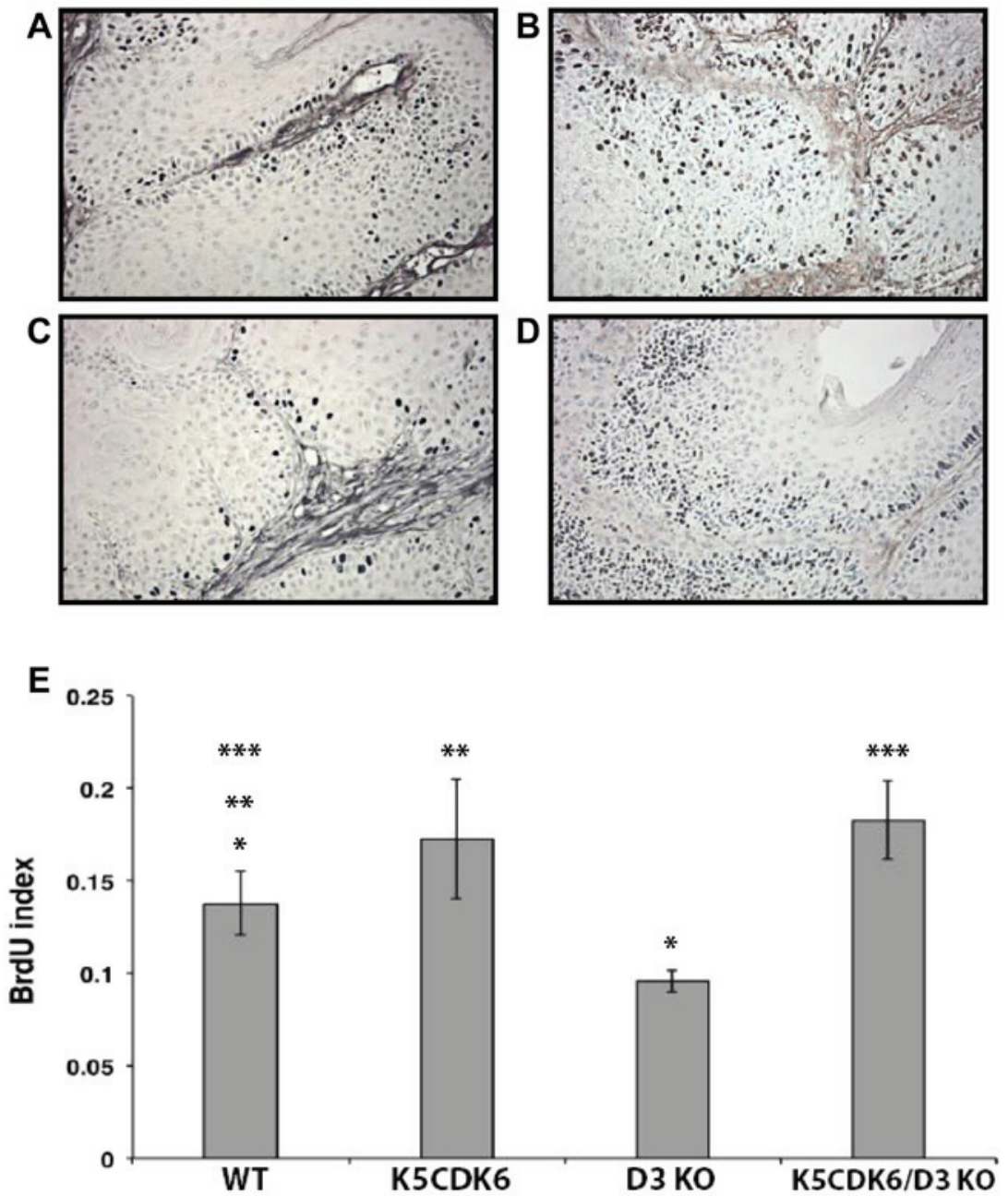

Figure 5. Cyclin D3 ablation reduces keratinocyte proliferation in skin papillomas. BrdU incorporation in papillomas from (A) WT, (B) K5CDK6, (C) D3 KO, and (D) K5CDK6/D3 KO mice. Magnification, x400. (E) Quantification of BrdU-positive cells in skin papillomas (BrdU label index) shows reduced proliferation in D3 KO tumors compared with WT papillomas ("P<0.05 D3 KO vs. wild-type controls, one-way ANOVA and Bonferroni's multiple comparisons test). Increased proliferation of K5CDK6 and K5CDK6/D3KO tumors compared with WT papillomas $\left({ }^{* *} \mathrm{P}<0.05\right.$, K5CDK6 vs. wild-type controls and ${ }^{* * *} \mathrm{P}<0.05$, $\mathrm{K} 5 \mathrm{CDK} 6 / \mathrm{D} 3 \mathrm{KO}$ vs. wild-type controls; one-way ANOVA and Bonferroni's multiple comparisons test). BrdU, bromodeoxyuridine; WT, wild-type; KO, knockout.

D1 complexes affect the rate of malignant progression, histopathological analysis of skin papillomas was performed. The dysplastic and anaplastic changes that included disturbed cell polarity (mainly on the basal cell layer), basal cell hyperplasia, disturbed differentiation sequence, increased number of mitosis, mitosis in suprabasal layers, abnormal mitosis, nuclear hyperchromatism, prominent nucleoli and increased nuclear/cytoplasmic ratio were all taken into account. Notably, $42 \%$ of papillomas from $\mathrm{K} 5 \mathrm{CDK} 6 /$ cyclin $^{\mathrm{D}} 3^{-/}$presented atypia in basal and certain suprabasal layers and lack of the differentiation pattern (intrapapilloma carcinoma and carcinoma in situ). By contrast, 14-15\% of wild-type and K5CDK6 papillomas displayed areas of intrapapilloma carcinoma, whereas all cyclin $\mathrm{D}^{-/}$papillomas were regular or moderately dysplastic (Table II). These results suggest that the increased level of CDK4/cyclin D1 and CDK6/cyclin D1 complexes in $\mathrm{K} 5 \mathrm{CDK} 6 /$ cyclin $\mathrm{D}^{-/}$mice may be associated with increased malignant progression. Supporting this hypothesis, previous data demonstrated that increased CDK4/cyclin D1 complexes led to increased malignant progression upon the overexpression of CDK4 in mouse epidermis $(25,33)$.

\section{Discussion}

Role of cyclin D3 in epidermal proliferation. Early studies by the authors have demonstrated that D-type cyclins are differently regulated in mouse epidermis $(22,23,27-30)$. Whereas cyclin D1 was upregulated in TPA-induced proliferative keratinocytes, cyclin D2 and cyclin D3 levels remained constant (27). In the present report, it was demonstrated that a lack of cyclin D3 expression does not affect keratinocyte proliferation. Consistent with this data, cyclin $\mathrm{D}^{-/}$and wild-type mice exhibited no differences in the total number of nucleated keratinocytes in the interfollicular epidermis. Moreover, histological analysis of skin sections revealed no changes in the skin structure of cyclin D $3^{-/}$mice. Biochemical analysis of epidermal lysates revealed an increased level of cyclin D1 protein and elevated formation of CDK4/cyclin D1 complexes. Therefore, epidermal keratinocytes proliferate normally in the absence of cyclin D3, likely through the formation of CDK4/6-cyclin D1 complexes, as a compensatory mechanism due to the lack of CDK4/6-cyclin D3 complexes. Although a lack of cyclin D3 expression does not alter the apoptotic 

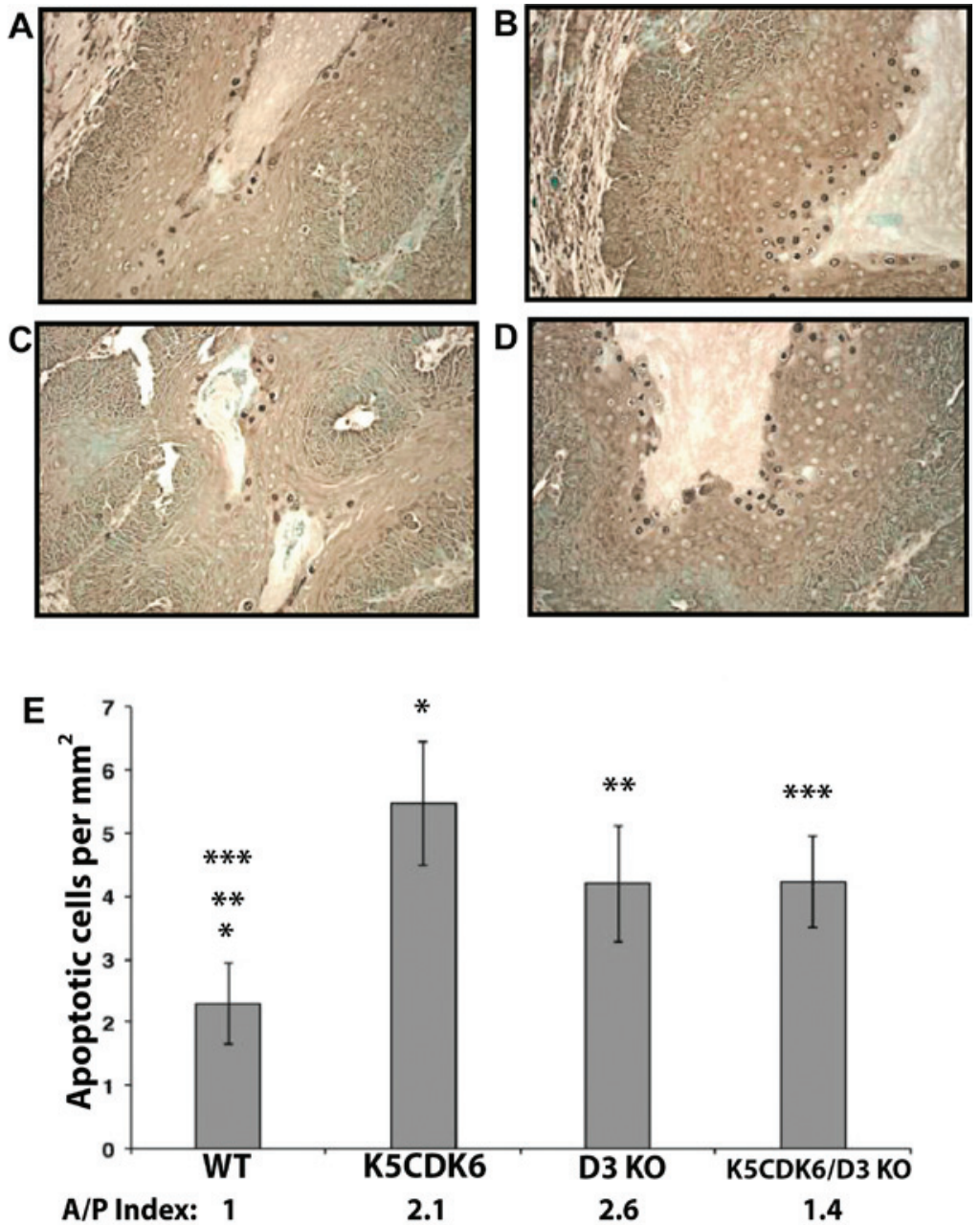

Figure 6. Increased apoptosis in skin papillomas from cyclin D3 ${ }^{--}$, K5CDK6 and K5CDK6/cyclin D3 ${ }^{--}$mice. Apoptotic cells were visualized by terminal deoxynucleotidyl transferase dUTP nick end labeling assay in papillomas from (A) WT, (B) K5CDK6, (C) D3 KO, and (D) K5CDK6/D3 KO mice. Magnification, $\mathrm{x} 400$. (E) Increased apoptosis in keratinocytes from K5CDK6, D3 KO, and K5CDK6/D3 KO tumors compared with WT papillomas ("P $<0.05$, K5CDK6 vs. wild-type controls, ${ }^{* *} \mathrm{P}<0.05$, D3 KO vs. wild-type controls, and ${ }^{* * *} \mathrm{P}<0.05, \mathrm{~K} 5 \mathrm{CDK} 6 / \mathrm{D} 3 \mathrm{KO}$ vs. wild-type controls; one-way ANOVA and Bonferroni's multiple comparisons test), $\mathrm{n}=10$ per group. The number of apoptotic cells and BrdU index were normalized to the wild-type samples, and the rate of apoptosis/proliferation was calculated (A/P Index). WT, wild-type; D3 KO, cyclin D3- mice; K5CDK6/D3 KO, K5CDK6/cyclin D3 ${ }^{-/}$mice.

index in the interfollicular epidermis, a relevant increase was observed in the number of apoptotic keratinocytes in the bulge area of the hair follicles. These results suggest that a lack of cyclin D3 expression affects the long-lived epithelial stem cells located within the bulge region. Fate-mapping experiments have demonstrated that these cells do not normally contribute to epidermal homeostasis (45), which explains why a lack of cyclin D3 does not affect the normal structure of epidermis. However, apoptosis in the bulge area of the hair follicle may affect re-epithelialization following wounding as epithelial injury leads to the recruitment of bulge-derived keratinocytes into the epidermis (45). Early studies by the authors and the results presented throughout this report demonstrated that the molecular mechanisms leading to compensatory changes in D-type cyclin levels respond only to modifications in cyclin D3, but not cyclin D1 or cyclin D2 $(29,50)$. In fact, transgenic expression of cyclin D3 is compensated by a reduction in levels of cyclin D2 (50), whereas a lack of cyclin D3 is compensated by overexpression of cyclin D1 (Fig. 3). The authors conclude that changes in the expression of cyclin D3 does not affect epidermal homeostasis, due to compensatory mechanisms by other members of the D-type cyclin family. However, increased levels of cyclin D1/cdk4 in cyclin D $3^{-/-}$epidermis led to hair follicle apoptosis in the bulge area, similar to results observed in retinoblastoma-null mice (40).

Cyclin D3 in skin tumorigenesis. The authors have previously reported that overexpression and ablation of D-type cyclins results in varied sensitivities to chemically induced mouse skin papillomas $(29,30,52,53)$. By using the two-stage carcinogenesis model, genetic evidence that ras-mediated skin tumor development depends on signaling pathways that act preferentially through cyclin D1 and cyclin D2 has been provided $(28,29,35)$. However, the role of cyclin D3 in skin carcinogenesis has not yet been defined. Substantial evidence has suggested that cells from the bulge area of hair follicles have characteristics similar to stem cells, including slow cycling, label-retaining properties and a high proliferative capacity (54-56). In this regard, Morris et al (47) demonstrated that bulge-area stem cells (BuSCs) retain carcinogen-DNA adducts, which supports the idea that these cells are targeted during chemical initiation $(47,57)$. The number of skin 
papillomas is associated with the number of initiated cells and/or other early events, including the clonal expansion of initiated cells. It was observed that cyclin D3 deletion and CDK6 overexpression (36) resulted in an increased number of hair follicles bearing apoptotic cells in the bulge region. Therefore, the authors hypothesized that cyclin D3 ablation leads to a reduced number of initiated cells and decreased skin papilloma development. To test this hypothesis, the two-stage carcinogenesis protocol was used, which allowed for study of the effect of cyclin D3 ablation during tumor initiation (an irreversible genetic alteration in a target cell), promotion (the process by which an initiated tissue develops focal proliferation leading to clonogenic expansion of the initiated cells), and malignant progression to SCC (the final transition to invasive behavior) (58). Supporting the hypothesis, a relevant reduction in multiplicity and incidence of papillomas was observed in cyclin D3-null mice compared with wild-type mice. Furthermore, $50 \%$ of cyclin $\mathrm{D}^{-/-}$mice remained refractory to papilloma development (Figs. 2 and 4). These results provide genetic evidence that a lack of cyclin D3 expression and a further increase in apoptosis in the bulge region of the hair follicle, affects the number of initiated cells or, alternatively, the clonal expansion of the initiated cells. Similarly, ablation of cyclin D1, cyclin D2, CDK4 and Skp2 led to a reduced number of papillomas due to failure during the initiation or early promotion stages $(28,29,32-34,36)$. Likewise, overexpression of CDK6 resulted in increased apoptosis in the bulge region of the hair follicle and inhibition of papilloma development (36).

The fact that cyclin D3 preferentially binds to CDK6 in mouse keratinocytes $(27,36)$ led to the hypothesis that the inhibitory action of CDK6 depends on cyclin D3. To test this hypothesis, $\mathrm{K} 5 \mathrm{CK} 6 /$ cyclin D3 $^{-/-}$compound mice were generated and subjected to a two-stage carcinogenesis protocol. Contrary to the hypothesis, the inhibition of papilloma formation driven by CDK6 expression and a lack of cyclin D3 did not act in a linear fashion, since a lack of cyclin D3 expression did not affect the tumor-repressing activity of CDK6. Cyclin D3 ablation resulted in the most substantial tumor inhibition, when compared with K5CDK6 and K5CDK6/cyclin D3 $3^{-/}$mice. The authors speculate that forced expression of CDK6 and increased formation of CDK6/cyclin D1 and CDK6/cyclin D3 complexes played a positive role during the clonal expansion of initiated cells in $\mathrm{K} 5 \mathrm{CDK} 6$ and $\mathrm{K} 5 \mathrm{CDK} 6 / \mathrm{D} 3^{-/-}$mice, but not in cyclin D3 ${ }^{-/}$mice. Supporting this view, CDK6/cyclin D3 and CDK6/cyclin D1 showed a faster kinetic of complex formation upon TPA treatment on mouse epidermis, compared with other D-type cyclin/CDKs complexes (27). The molecular mechanisms by which alterations in the kinetics of CDK/D-type cyclin complex formation affects the clonogenic expansion of the initiated cells remains unclear and is beyond the scope of the present study. Similar to the cyclin $\mathrm{D} 3^{-/-}$model, ablation of $\mathrm{Rb}$, the primary substrate of CDK4 and CDK6, in the mouse epidermis also resulted in increased apoptosis and a reduction in the number of papillomas (40). Altogether, the results of the present study and from the epidermal-specific $\mathrm{Rb}^{-/}$mice (40) support a model in which the phosphorylation/inactivation of $\mathrm{Rb}$ by elevated CDK activity leads to apoptosis in BuSCs with the consequent reduction in the number of skin papillomas. The likelihood that CDKs and/or D-type cyclins exert their tumor inhibitory effect through $\mathrm{Rb}$-independent mechanisms cannot be ruled out. In this regard, it has been reported that CDK6 is part of a transcription complex that induces the expression of the tumor suppressor p16 ${ }^{\text {Ink4 }}(59)$. Whether this kinase-independent function of CDK6 is active in keratinocytes and BuSCs is unknown. However, the authors hypothesize that downregulation of D-type cyclins results in elevation of the free-CDK6 and its transcription activity, leading to the blockage of the expansion of initiated cells via p16 ${ }^{\text {Ink4a }}$ transcription. In the last 5 years, a number of non-canonical functions of D-type cyclins as transcription factors have been described $(60,61)$. For instance, the transcription factor Runx1 is negatively regulated by cyclin D3 in a kinase-independent manner (62). Runx1 promotes the proliferation of hair follicle stem cells and induces epithelial tumor formation in mouse skin (63). Therefore, a lack of and/or overexpression of cyclin D3 may unbalance the apoptotic/proliferative rate in BuSCs, with a direct impact on the rate of tumor formation.

Histopathological analysis of skin tumors indicated that simultaneous overexpression of CDK6 and a lack of cyclin D3 expression resulted in an increased rate of malignant progression. The $\mathrm{K} 5 \mathrm{CDK} 6 / \mathrm{D}^{-/-}$mice developed more aggressive tumors and $42 \%$ were classified as premalignant papillomas or SCC, whereas only $15 \%$ of K5CDK6 and 14\% of wild-type tumors exhibited similar characteristics (Table II). Cyclin D3 $3^{-/-}$tumors were classified as regular papillomas with no atypia in the basal layers and no invasion of epidermis cells into the dermis. Biochemical analysis of epidermal lysates from $\mathrm{K} 5 \mathrm{CDK} 6 /$ cyclin $\mathrm{D} 3^{-/}$mice revealed elevated levels of CDK6/cyclin D1 and CDK4/cyclin $\mathrm{D} 1$ complexes, whereas cyclin $\mathrm{D} 3^{-/-}$epidermis only displayed elevated levels of CDK4/cyclin D1 complexes (Table I). Similarly, it has been previously reported that increased CDK4 expression in $\mathrm{K} 5 \mathrm{CDK} 4$ transgenic mice induces malignant progression of skin papillomas $(25,44)$. Notably, the malignant progression observed in $\mathrm{K} 5 \mathrm{CDK} 4$ mice was partially mediated via $27^{\mathrm{Kip} 1}$ sequestration by the $\mathrm{CDK} /$ cyclin complexes and the indirect activation of CDK2 $(25,44)$. Therefore, data of the present study suggest that the simultaneous increase in the level of CDK4/cyclin D1 and CDK6/cyclin D1 complexes observed in $\mathrm{K} 5 \mathrm{CDK} 6 /$ cyclin $\mathrm{D}^{-/-}$mice may result in $\mathrm{CDK} 2$ activation, leading to increased malignant progression.

Collectively, the results of the present study indicate that the absence of cyclin D3 leads to decreased papilloma formation in mouse epidermis due to increase apoptosis in the bulge region of the hair follicle. These observations indicate that regulation of cell survival of BuSC is a crucial mechanism for crippling cellular defense against neoplasia. The data of the present study suggest that cyclin D3 inhibition blocks an early event of the multistage process of non-melanoma skin tumorigenesis. Although cyclin D3 binds preferentially to CDK6 (27), the tumor inhibition mediated by CDK6 is independent of cyclin D3. Finally, the present study indicates that the unbalanced formation of CDK4/6-D-type cyclin complexes leads to reduced papilloma development and may result in a more aggressive tumor phenotype, increasing malignant progression.

\section{Acknowledgements}

The authors thank Ms. Rima Majumdar (North Carolina State University, College of Veterinary Medicine, Raleigh, NC, USA) for her technical support, Dr Piotr Sicinski and Dr Ewa 
Sicinska (Harvard Medical School, Department of Genetics, Boston, MA, USA) for providing the cyclin D3-null mice, the Laboratory Animal Resources and the Histology Core at the College of Veterinary Medicine, North Carolina State University for aiding with the processing and staining of skin and tumor samples. The present study was supported by NIEHS (award no. P30ES025128) Center for Human Health and the Environment.

\section{References}

1. Sherr CJ: D-type cyclins. Trends Biochem Sci 20: 187-190, 1995.

2. Weinberg RA: The retinoblastoma protein and cell cycle control. Cell 81: 323-330, 1995.

3. Farkas T, Hansen K, Holm K, Lukas J and Bartek J: Distinct phosphorylation events regulate p130- and p107-mediated repression of E2F-4. J Biol Chem 277: 26741-26752, 2002.

4. Leng X, Noble M, Adams PD, Qin J and Harper JW: Reversal of growth suppression by p107 via direct phosphorylation by cyclin D1/cyclin-dependent kinase 4. Mol Cell Biol 22: 2242-2254, 2002.

5. Meyerson M and Harlow E: Identification of G1 kinase activity for cdk6, a novel cyclin D partner. Mol Cell Biol 14: 2077-2086, 1994.

6. Sherr CJ and Roberts JM: CDK inhibitors: Positive and negative regulators of G1-phase progression. Genes Dev 13: 1501-1512, 1999.

7. Blain SW, Montalvo E and Massague J: Differential interaction of the cyclin-dependent kinase (Cdk) inhibitor p27Kip1 with cyclin A-Cdk2 and cyclin D2-Cdk4. J Biol Chem 272: 25863-25872, 1997.

8. Sherr CJ and McCormick F: The RB and $\mathrm{p} 53$ pathways in cancer. Cancer Cell 2: 103-112, 2002.

9. Ciemerych MA, Kenney AM, Sicinska E, Kalaszczynska I, Bronson RT, Rowitch DH, Gardner H and Sicinski P: Development of mice expressing a single D-type cyclin. Genes Dev 16: 3277-3289, 2002.

10. Cheung TH, Yu MM, Lo KW, Yim SF, Chung TK and Wong YF: Alteration of cyclin D1 and CDK4 gene in carcinoma of uterine cervix. Cancer Lett 166: 199-206, 2001.

11. Dickson C, Fantl V, Gillett C, Brookes S, Bartek J, Smith R, Fisher C, Barnes D and Peters G: Amplification of chromosome band 11q13 and a role for cyclin D1 in human breast cancer. Cancer Lett 90: 43-50, 1995.

12. Fujii M, Ishiguro R, Yamashita T and Tashiro M: Cyclin D1 amplification correlates with early recurrence of squamous cell carcinoma of the tongue. Cancer Lett 172: 187-192, 2001.

13. Houldsworth J, Reuter V, Bosl GJ and Chaganti RS: Aberrant expression of cyclin D2 is an early event in human male germ cell tumorigenesis. Cell Growth Differ 8: 293-299, 1997.

14. Sicinski P, Donaher JL, Geng Y, Parker SB, Gardner H, Park MY, Robker RL, Richards JS, McGinnis LK, Biggers JD, et al: Cyclin D2 is an FSH-responsive gene involved in gonadal cell proliferation and oncogenesis. Nature 384: 470-474, 1996.

15. Delmer A, Ajchenbaum-Cymbalista F, Tang R, Ramond S, Faussat AM, Marie JP and Zittoun R: Overexpression of cyclin D2 in chronic B-cell malignancies. Blood 85: 2870-2876, 1995.

16. Hedberg Y, Roos G, Ljungberg B and Landberg G: Cyclin D3 protein content in human renal cell carcinoma in relation to cyclin D1 and clinico-pathological parameters. Acta Oncol 41: 175-181, 2002.

17. Ito $\mathrm{Y}$, Takeda $\mathrm{T}$, Wakasa $\mathrm{K}$, Tsujimoto $\mathrm{M}$ and Matsuura $\mathrm{N}$ : Expression and possible role of cyclin D3 in human pancreatic adenocarcinoma. Anticancer Res 21: 1043-1048, 2001.

18. Pruneri G, Pignataro L, Valentini S, Fabris S, Maisonneuve P, Carboni N, Pece S, Capra M, Del Curto B, Neri A and Viale G: Cyclin D3 immunoreactivity is an independent predictor of survival in laryngeal squamous cell carcinoma. Clin Cancer Res 11: 242-248, 2005.

19. Wong SC, Chan JK, Lee KC and Hsiao WL: Differential expression of p16/p21/p27 and cyclin D1/D3, and their relationships to cell proliferation, apoptosis, and tumour progression in invasive ductal carcinoma of the breast. J Pathol 194: 35-42, 2001

20. Filipits M, Jaeger U, Pohl G, Stranzl T, Simonitsch I, Kaider A, Skrabs C and Pirker R: Cyclin D3 is a predictive and prognostic factor in diffuse large B-cell lymphoma. Clin Cancer Res 8: $729-733,2002$
21. Sicinska E, Aifantis I, Le Cam L, Swat W, Borowski C, Yu Q, Ferrando AA, Levin SD, Geng Y, von Boehmer H and Sicinski P: Requirement for cyclin D3 in lymphocyte development and T cell leukemias. Cancer Cell 4: 451-461, 2003.

22. Rodriguez-Puebla ML, LaCava M and Conti C: Cyclin d1 overexpression in mouse epidermis increases cyclin-dependent kinase activity and cell proliferation in vivo but does not affect skin tumor development. Cell Growth Differ 10: 467-472, 1999.

23. Rodriguez-Puebla ML, LaCava M, Gimenez-Conti IB, Jonhson DG and Conti CJ: Deregulated expression of cell-cycle proteins during premalignant progression in SENCAR mouse skin. Oncogene 17: 2251-2258, 1998.

24. Rodriguez-Puebla ML, Miliani de Marval PL, LaCava M, Moons DS, Kiyokawa $\mathrm{H}$ and Conti CJ: Cdk4 deficiency inhibits skin tumor development but does not affect keratinocyte proliferation. Am J Pathol 161: 405-411, 2002.

25. Miliani de Marval PL, Macias E, Conti CJ and Rodriguez-Puebla ML: Enhanced malignant tumorigenesis in Cdk4 transgenic mice. Oncogene 23: 1863-1873, 2004.

26. Zhang SY, Liu SC, Goodrow T, Morris R and Klein-Szanto AJ: Increased expression of G1 cyclins and cyclin-dependent kinases during tumor progression of chemically induced mouse skin neoplasms. Mol Carcinog 18: 142-152, 1997.

27. Rodriguez-Puebla ML, Robles AI, Johnson DG, LaCava M and Conti CJ: Synchronized proliferation induced by 12-O-tetradecanoylphorbol-13-acetate treatment of mouse skin: An in vivo model for cell cycle regulation. Cell Growth Differ 9: 31-39, 1998.

28. Robles AI, Rodriguez-Puebla ML, Glick AB, Trempus C, Hansen L, Sicinski P, Tennant RW, Weinberg RA, Yuspa SH and Conti CJ: Reduced skin tumor development in cyclin D1-deficient mice highlights the oncogenic ras pathway in vivo. Genes Dev 12: 2469-2474, 1998.

29. Rojas P, Cadenas MB, Lin PC, Benavides F, Conti CJ and Rodriguez-Puebla ML: Cyclin D2 and cyclin D3 play opposite roles in mouse skin carcinogenesis. Oncogene 26: 1723-1730, 2007.

30. Rodriguez-Puebla ML, LaCava M and Conti CJ: Cyclin D1 overexpression in mouse epidermis increases cyclin-dependent kinase activity and cell proliferation in vivo but does not affect skin tumor development. Cell Growth Differ 10: 467-472, 1999.

31. Rodriguez-Puebla ML, Robles AI and Conti CJ: ras activity and cyclin D1 expression: An essential mechanism of mouse skin tumor development. Mol Carcinog 24: 1-6, 1999.

32. Rodriguez-Puebla ML, Miliani de Marval PL, LaCava M, Moons DS, Kiyokawa H and Conti CJ: Cdk4 deficiency inhibits skin tumor development but does not affect normal keratinocyte proliferation. Am J Pathol 161: 405-411, 2002.

33. Macias E, Kim Y, Miliani de Marval PL, Klein-Szanto A and Rodriguez-Puebla ML: Cdk2 deficiency decreases ras/CDK4-dependent malignant progression, but not myc-induced tumorigenesis. Cancer Res 67: 9713-9720, 2007.

34. Sistrunk C, Kim SH, Wang X, Lee SH, Kim Y, Macias E and Rodriguez-Puebla ML: Skp2 deficiency inhibits chemical skin tumorigenesis independent of p27(Kip1) accumulation. Am J Pathol 182: 1854-1864, 2013.

35. Wang X, Sistrunk C, Miliani de Marval PL, Kim Y and Rodriguez-Puebla ML: Combined effect of cyclin D3 expression and abrogation of cyclin D1 prevent mouse skin tumor development. Cell Cycle 11: 335-342, 2012.

36. Wang X, Sistrunk C and Rodriguez-Puebla ML: Unexpected reduction of skin tumorigenesis on expression of cyclin-dependent kinase 6 in mouse epidermis. Am J Pathol 178: 345-354, 2011.

37. Philipp J, Vo K, Gurley KE, Seidel K and Kemp CJ: Tumor suppression by p27Kip1 and p21Cip1 during chemically induced skin carcinogenesis. Oncogene 18: 4689-4698, 1999.

38. Kemp CJ, Donehower LA, Bradley A and Balmain A: Reduction of $\mathrm{p} 53$ gene dosage does not increase initiation or promotion but enhances malignant progression of chemically induced skin tumors. Cell 74: 813-822, 1993.

39. Ise K, Nakamura K, Nakao K, Shimizu S, Harada H, Ichise T, Miyoshi J, Gondo Y, Ishikawa T, Aiba A and Katsuki M: Targeted deletion of the $\mathrm{H}$-ras gene decreases tumor formation in mouse skin carcinogenesis. Oncogene 19: 2951-2956, 2000.

40. Ruiz S, Santos M, Lara MF, Segrelles C, Ballestín C and Paramio JM: Unexpected roles for $\mathrm{pRb}$ in mouse skin carcinogenesis. Cancer Res 65: 9678-9686, 2005.

41. Ruiz S, Santos M and Paramio JM: Is the loss of $\mathrm{pRb}$ essential for the mouse skin carcinogenesis? Cell Cycle 5: 625-629, 2006. 
42. Rojas P, Benavides F, Blando J, Perez C, Cardenas K, Richie E, Knudsen ES, Johnson DG, Senderowicz AM, Rodriguez-Puebla ML and Conti CJ: Enhanced skin carcinogenesis and lack of thymus hyperplasia in transgenic mice expressing human cyclin D1b (CCND1b). Mol Carcinog 48: 508-516, 2009.

43. Rounbehler RJ, Schneider-Broussard R, Conti CJ and Johnson DG: Myc lacks E2F1's ability to suppress skin carcinogenesis. Oncogene 20: 5341-5349, 2001.

44. Macias E, Miliani de Marval PL, De Siervi A, Conti CJ, Senderowicz AM and Rodriguez-Puebla ML: CDK2 activation in mouse epidermis induces keratinocyte proliferation but does not affect skin tumor development. Am J Pathol 173: 526-535, 2008.

45. Ito M, Liu Y, Yang Z, Nguyen J, Liang F, Morris RJ and Cotsarelis G: Stem cells in the hair follicle bulge contribute to wound repair but not to homeostasis of the epidermis. Nat Med 11: 1351-1354, 2005

46. Wang P, Pavletic ZS and Joshi SS: Increased apoptosis in B-chronic lymphocytic leukemia cells as a result of cyclin D3 down regulation. Leuk Lymphoma 43: 1827-1835, 2002.

47. Morris RJ, Fischer SM and Slaga TJ: Evidence that a slowly cycling subpopulation of adult murine epidermal cells retains carcinogen. Cancer Res 46: 3061-3066, 1986.

48. Lapouge G, Youssef KK, Vokaer B, Achouri Y, Michaux C, Sotiropoulou PA and Blanpain C: Identifying the cellular origin of squamous skin tumors. Proc Natl Acad Sci USA 108: 7431-7436, 2011.

49. Rodriguez-Puebla ML, LaCava M, Gimenez-Conti IB, Johnson DG and Conti CJ: Deregulated expression of cell-cycle proteins during premalignant progression in SENCAR mouse skin. Oncogene 17: 2251-2258, 1998.

50. Rodriguez-Puebla ML, LaCava M, Miliani De Marval PL, Jorcano JL, Richie ER and Conti CJ: Cyclin D2 overexpression in transgenic mice induces thymic and epidermal hyperplasia whereas cyclin D3 expression results only in epidermal hyperplasia. Am J Pathol 157: 1039-1050, 2000.

51. Ito K, Maruyama Z, Sakai A, Izumi S, Moriishi T, Yoshida CA, Miyazaki T, Komori H, Takada K, Kawaguchi H and Komori T: Overexpression of Cdk6 and Cend1 in chondrocytes inhibited chondrocyte maturation and caused p53-dependent apoptosis without enhancing proliferation. Oncogene 33: 1862-1871, 2014.

52. Yamamoto $H$, Ochiya $T$, Takeshita $F$, Toriyama-Baba $H$ Hirai K, Sasaki H, Sasaki H, Sakamoto H, Yoshida T, Saito I and Terada M: Enhanced skin carcinogenesis in cyclin D1-conditional transgenic mice: Cyclin D1 alters keratinocyte response to calcium-induced terminal differentiation. Cancer Res 62 1641-1647, 2002.
53. Robles AI, Larcher F, Whalin RB, Murillas R, Richie E, Gimenez-Conti IB, Jorcano JL and Conti CJ: Expression of Cyclin D1 in epithelial tissues of transgenic mice results in epidermal hyperproliferation and severe thymic hyperplasia. Proc Natl Acad Sci USA. 93: 7634-7638, 1996.

54. Morris RJ, Tryson KA and Wu KQ: Evidence that the epidermal targets of carcinogen action are found in the interfollicular epidermis of infundibulum as well as in the hair follicles. Cancer Res 60: 226-229, 2000.

55. Morris RJ, Liu Y, Marles L, Yang Z, Trempus C, Li S, Lin JS, Sawicki JA and Cotsarelis G: Capturing and profiling adult hair follicle stem cells. Nat Biotechnol 22: 411-417, 2004.

56. Morris RJ: A perspective on keratinocyte stem cells as targets for skin carcinogenesis. Differentiation 72: 381-386, 2004.

57. Kangsamaksin T, Park HJ, Trempus CS and Morris RJ: A perspective on murine keratinocyte stem cells as targets of chemically induced skin cancer. Mol Carcinog 46: 579-584, 2007.

58. Slaga T: Mechanism involved in two-stage carcinogenesis in mouse skin. In: Mechanism of Tumor Promotion. Slaga T (ed.) CRC Press, Boca Raton, pp1-16, 1984.

59. Kollmann K, Heller G, Schneckenleithner C, Warsch W, Scheicher R, Ott RG, Schäfer M, Fajmann S, Schlederer M, Schiefer AI, et al: A Kinase-Independent Function of CDK6 Links the Cell Cycle to Tumor Angiogenesis. Cancer Cell 24: 167-181, 2013.

60. Hydbring P, Malumbres M and Sicinski P: Non-canonical functions of cell cycle cyclins and cyclin-dependent kinases. Nat Rev Mol Cell Biol 17: 280-292, 2016.

61. Pestell RG: New roles of cyclin D1. Am J Pathol 183: 3-9, 2013.

62. Peterson LF, Boyapati A, Ranganathan V, Iwama A, Tenen DG, Tsai S and Zhang DE: The hematopoietic transcription factor AML1 (RUNX1) is negatively regulated by the cell cycle protein cyclin D3. Mol Cell Biol 25: 10205-10219, 2005.

63. Hoi CS, Lee SE, Lu SY, McDermitt DJ, Osorio KM, Piskun CM, Peters RM, Paus R and Tumbar T: Runx1 directly promotes proliferation of hair follicle stem cells and epithelial tumor formation in mouse skin. Mol Cell Biol 30: 2518-2536, 2010. 